\title{
Correction \\ Correction: Atkinson, D.; Becker, T. A 117 Line 2D Digital Image Correlation Code Written in MATLAB. Remote Sens. 2020, 12, 2906
}

\author{
Devan Atkinson (D) and Thorsten Becker*(D)
}

check for

updates

Citation: Atkinson, D.; Becker, T. Correction: Atkinson, D.; Becker, T. A 117 Line 2D Digital Image Correlation Code Written in MATLAB. Remote Sens. 2020, 12, 2906. Remote Sens. 2021, 13, 1964. https://doi.org/10.3390/ rs13101964

Received: 18 March 2021

Accepted: 29 March 2021

Published: 18 May 2021

Publisher's Note: MDPI stays neutral with regard to jurisdictional claims in published maps and institutional affiliations.

Copyright: (c) 2021 by the authors. Licensee MDPI, Basel, Switzerland. This article is an open access article distributed under the terms and conditions of the Creative Commons Attribution (CC BY) license (https:/ / creativecommons.org/licenses/by/ $4.0 /)$.
Department of Mechanical and Mechatronic Engineering, Stellenbosch University, Corner of Banghoek and Joubert Street, Stellenbosch, Western Cape 7599, South Africa; 17732913@sun.ac.za

* Correspondence: tbecker@sun.ac.za

The authors wish to make the following corrections to the paper [1].

1. There was a typing error in the original article in Section 2.1.2, paragraph 3, line 6. The value of $c_{S}$ was reported as one $\left(c_{s}=1\right)$. It should have been reported with a value of zero $\left(c_{s}=0\right)$. Section 2.1.2, paragraph 3 , line 6 should read as: "Here, $c_{S}=0$ since an orthogonal sensor CS is assumed."

2. There was a typing error in the original article. A line of text was omitted at the beginning of Appendix A. Prior to presenting the code, a line of text should read as "The ADIC2D code can be accessed on GitHub at https:/ / github.com/SUMatEng/ ADIC2D."

3. There was a typing error in the original article. A line in the code provided in Appendix A is missing. Line 12 of function SubShapeExtract (Appendix A, paragraph 3) read "12 [dX,dY]=meshgrid (-(SubSize-1)/2:(SubSize-1)/2,", whereas it should read "12 [dX,dY]=meshgrid(-(SubSize-1)/2:(SubSize-1)/2,-(SubSize-1)/2:(SubSize1) /2);"

The authors apologize for any inconvenience caused and state that the scientific conclusions are unaffected. The original article has been updated.

\section{Reference}

1. Atkinson, D.; Becker, T. A 117 Line 2D Digital Image Correlation Code Written in MATLAB. Remote Sens. 2020, 12, 2906. [CrossRef] 